\title{
Chlorinated Withanolides from Withania somnifera
}

\author{
Xiaoqin Tong, Huaping Zhang, and Barbara N. Timmermann * \\ Department of Medicinal Chemistry, University of Kansas, Lawrence, Kansas 66045, United \\ States
}

\begin{abstract}
A chlorinated withanolide, $6 \alpha$-chloro-5 $\beta, 17 \alpha$-dihydroxywithaferin $\mathrm{A}(\mathbf{1})$, and nine known withanolides, $6 \alpha$-chloro- $5 \beta$-hydroxywithaferin A (2), (22R)-5 $\beta$-formyl-6 $\beta, 27$-dihydroxy-1-oxo-4norwith-24-enolide, withaferin A, 2,3-dihydrowithaferin A, 3-methoxy-2,3-dihydrowithaferin A, 2,3-didehydrosomnifericin, withanone, withanoside IV and withanoside $\mathrm{X}$, were isolated from Withania somnifera (Solanaceae). All structures were elucidated on the basis of spectroscopic methods (IR, HRESIMS, 1D/2D NMR). X-ray crystallography confirmed the absolute configuration of $\mathbf{1}$.
\end{abstract}

\section{Keywords}

Chlorinated withanolide; Withania somnifera; Solanaceae; NMR; Crystal structure

\section{Introduction}

\begin{abstract}
Withanolides are a group of naturally occurring $\mathrm{C}_{28}$-steroidal lactones built on an intact or rearranged ergostane scaffold in which C-22 and C-26 are appropriately oxidized to form a $\delta$-lactone ring on the nine-carbon side chain. These compounds are mainly found in members of the plant family Solanaceae (Mirjalili et al., 2009) and are known to possess various biological activities including anticarcinogenic (Christina et al., 2004), antioxidant (Bhattacharya et al., 1997), adaptogenic (Dhuley, 2000), antiparkinsonism (Nagashayana et al., 2000), antibacterial (Arora et al., 2004), anti-inflammatory (Al-Hindawi et al., 1989), immunomodulatory (Davis and Kuttan, 2000) and antidepressant (Bhattacharya et al., 2000) effects. As part of our ongoing investigation of antiproliferative withanolides (Samadi et al., 2010), we selected Withania somnifera L. Dunal as an abundant source of these compounds.

W. somnifera, commonly known as "ashwagandha" and widely cultivated in the drier parts of India, is well known for its use in Ayurvedic medicine. Previous research supports its pharmacological uses, confirming antioxidant, anti-inflammatory (Sumantran et al., 2008), immunomodulatory, anticarcinogenic, antibacterial (Owais et al., 2005), antiparkinsonism (Sankar et al., 2007) and antistress (Geetha and Harish, 2006) properties. Raw plant material and extracts of this species are currently sold as dietary supplements in the USA for
\end{abstract}

\footnotetext{
(C) 2011 Phytochemical Society of Europe. Published by Elsevier Ltd. All rights reserved.

*Corresponding author. Tel: (785) 864-4844. Fax: (785) 864-5326. btimmer@ku.edu. (B. N. Timmermann).

Supplemental Data: LC-MS of PhycoMyco crude extract of $W$. somnifera using withaferin A and withanone as markers; X-ray crystallography analysis, ${ }^{1} \mathrm{H}$ NMR, and MS spectra as well as HPLC analysis of $\mathbf{1}$ and ${ }^{1} \mathrm{H}$ NMR of $\mathbf{2}$. This material is available free of charge via the internet.

Publisher's Disclaimer: This is a PDF file of an unedited manuscript that has been accepted for publication. As a service to our customers we are providing this early version of the manuscript. The manuscript will undergo copyediting, typesetting, and review of the resulting proof before it is published in its final citable form. Please note that during the production process errors may be discovered which could affect the content, and all legal disclaimers that apply to the journal pertain.
} 
increasing energy and endurance, strengthening immune function, and helping the body overcome imbalance. More than 130 withanolides have been reported in previous investigations from the same species. Herein, we report the isolation and structural elucidation of a new chlorinated withanolide (1), named $6 \alpha$-chloro-5 $\beta, 17 \alpha$ dihydroxywithaferin A (Fig. 1), along with other nine known withanolides.

\section{Results and discussion}

The ethyl acetate-soluble fraction of the crude extract acquired for this study was subjected to repeated column chromatography to yield compound $\mathbf{1}$. Compound $\mathbf{1}$ was obtained as colorless parallelepiped-shaped crystals by recrystallization from $\mathrm{MeOH}-\mathrm{CH}_{2} \mathrm{Cl}_{2}-\mathrm{EtOAc}$ (5:1:1). The molecular formula $\mathrm{C}_{28} \mathrm{H}_{39} \mathrm{ClO}_{7}$ was deduced from its HRESIMS (observed $\mathrm{m} / \mathrm{z}$ $523.2440[\mathrm{M}+\mathrm{H}]^{+}$, calcd for $\left.\mathrm{C}_{28} \mathrm{H}_{40} \mathrm{ClO}_{7} 523.2463\right)$ and NMR data. The presence of chlorine was supported by the intensity of the $[\mathrm{M}+\mathrm{H}+2]^{+}$peak, which was approximately one-third as intense as the pseudomolecular ion peak $[\mathrm{M}+\mathrm{H}]^{+}$. IR absorption bands at 3500,1700 , and $1650 \mathrm{~cm}^{-1}$ revealed the presence of $\mathrm{OH}$, carbonyl and lactonic groups.

The ${ }^{13} \mathrm{C}$ NMR (DEPT) spectrum of $\mathbf{1}$ displayed 28 signals which were assigned to four methyl, seven methylene (including one oxygenated at $\delta 57.3$ ), nine methine (including two olefins at $\delta 127.8$ and 142.8), and eight quaternary carbons (including one keto carbonyl at $\delta 200.2$ and one ester carbonyl at $\delta 167.0$, two olefins at $\delta 154.2$ and 125.2, two oxygenated at $\delta 84.8$ and 78.1) corresponding to $\mathrm{C}_{28} \mathrm{H}_{35}$. Thus, the remaining four hydrogen atoms were assigned to four $\mathrm{OH}$ groups. These data were consistent with the characteristic features of withanolides, $\mathrm{C}_{28}$-steroidal lactones with a $\delta$-lactone ring on the nine-carbon side chain.

The ${ }^{1} \mathrm{H}$ NMR spectrum of $\mathbf{1}$ also showed typical signals for a withanolide. The four methyl groups resonated at $\delta 0.99(3 \mathrm{H}, \mathrm{d}, J=7.0 \mathrm{~Hz}), \delta 0.78(3 \mathrm{H}, \mathrm{s}), \delta 1.27(3 \mathrm{H}, \mathrm{s})$, and $\delta 2.03(3 \mathrm{H}$, $\mathrm{s}$ ), corresponding to the secondary methyl of C-21 and the quaternary methyls $\mathrm{C}-18,19$ and 28 of a withanolide.

The NMR data of $\mathbf{1}$ was very similar to those of another chlorinated withanolide, $6 \alpha-$ chloro-5 $\beta$-hydroxywithaferin A 2 (Nittala et al., 1981), isolated during this study. The obvious difference between $\mathbf{1}$ and $\mathbf{2}$ was the presence of a quaternary carbon $(\delta 84.8)$ in $\mathbf{1}$ and a methine carbon (C-17) in the latter $\left({ }^{1} \mathrm{H}\right.$ NMR $\delta 1.07,{ }^{13} \mathrm{C}$ NMR $\left.\delta 51.8\right)$, suggesting that 1 was a 17 -hydroxy derivative of $\mathbf{2}$. This observation was supported by the high-frequency shift of C-13 ( $\delta 48.3$ in $\mathbf{1}$ and $\delta 43.2$ in 2), C-16 ( $\delta 36.5$ in $\mathbf{1}$ and $\delta 27.2$ in 2), and C-20 ( $\delta 42.6$ in 1 and $\delta 38.7$ in 2) in the ${ }^{13} \mathrm{C}$ NMR spectra. It was also supported by the ${ }^{1} \mathrm{H}-{ }^{1} \mathrm{H}$ COSY and HSQC spectra (a fragment $\mathrm{CH}_{3}-\mathrm{CH}-\mathrm{CH}(\mathrm{O})-\mathrm{CH}_{2}$ - of the side chain linked to the oxygenated quaternary $\mathrm{C}-17$ in $\mathbf{1}$ and a fragment $\mathrm{CH}_{3}-\mathrm{CH}-\mathrm{CH}(\mathrm{O})-\mathrm{CH}_{2}$ - of the side chain linked to methine $\mathrm{C}-17$ in 2), and the HMBC correlations (Fig. 2) between $\mathrm{H}_{3}-21(\delta 0.99)$ and $\mathrm{C}-17$ $(\delta 84.8)$, between $\mathrm{H}_{3}-18(\delta 0.78)$ and C-17 ( $\left.\delta 84.8\right)$ in $\mathbf{1}$. The full assignments of NMR data (Table 1) were obtained by 2D NMR including ${ }^{1} \mathrm{H}-{ }^{1} \mathrm{H}$ COSY, HSQC and HMBC spectra.

Finally, the structure of $\mathbf{1}$ was confirmed through single-crystal X-ray diffraction experiments (Fig. 3). The absolute configuration of $\mathbf{1}$ was confirmed on the basis of anomalous scattering of the chlorine atoms in the crystal. Thus, the structure of the new withanolide 1 was established as $6 \alpha$-chloro-5 $\beta, 17 \alpha$-dihydroxywithaferin A.

The known compounds were identified, by comparison of their NMR and MS data with those reported in the literature, as $6 \alpha$-chloro- $5 \beta$-hydroxywithaferin A (2) (Nittala et al., 1981); (22R)-5 $\beta$-formyl-6 $\beta, 27$-dihydroxyl-1-oxo-4-norwith-24-enolide (Nittala and Lavie, 1982); withaferin A, 2,3-dihydrowithaferin A and 3-methoxy-2,3-dihydrowithaferin A (Pelletier et al., 1979); 2,3-didehydrosomnifericin (Choudhary et al., 1996); withanone (Gottlieb and Kirson, 1981); withanoside IV (Matsuda et al., 2001) and withanoside X 
(Zhao et al., 2002). Full assignments of NMR data for the known chlorinated withanolide 2 were listed in Table 1 because those values reported in the literature (Nittala et al., 1981) and, especially the assignments of its ${ }^{13} \mathrm{C}$ NMR data $(\mathrm{C}-4,6,10,14,17)$, need to be revised.

Chlorinated compounds such as $\mathbf{1}$ and $\mathbf{2}$ are not commonly encountered in higher plants. To date, only five other chlorinated withanolides have been reported from W. somnifera, including withanolide C (Bessalle and Lavie, 1992), withanolide Z (Pramanick et al., 2008), $6 \alpha$-chloro-5 $\beta$-hydrowithanolide D, 4-deoxyphysalolactone (Nittala et al., 1981) and 27acetoxy-5 $\beta$-chloro- $6 \alpha$-hydroxywithaferin A (Choudhary et al., 2010). With the exception of 27 -acetoxy-5 $\beta$-chloro- $6 \alpha$-hydroxywithaferin $\mathrm{A}$ and withanolide $\mathrm{Z}$, all the reported chlorinated withanolides contain a $6 \alpha$-chloro- $5 \beta$-hydroxy system. This suggests that the epoxide rings that are usually encountered at C-5 and C-6 have undergone a diaxial opening (Nittala et al., 1981).

\section{Experimental}

\subsection{General}

Optical rotations were obtained on a Rudolph Research Analytical Autopol IV Automatic polarimeter. Melting points were recorded using a MPA100 OptiMelt Automated Melting Point System (Stanford Research Systems, Sunnyvale, CA). UV data were acquired using an Agilent Technologies 1200 HPLC (Diode Array Detector). HPLC was conducted on Agilent Technologies 1200 series system. IR data were obtained using a Thermo Nicolet Avatar 360 FT-IR instrument. NMR spectra were recorded on either a Bruker DRX-400 with a qnp probe or on a Bruder AV-500 with a cryoprobe. ${ }^{1} \mathrm{H}$ and ${ }^{13} \mathrm{C}$ spectra were recorded using the residual protonated signal in the $\mathrm{CDCl}_{3}$ solvent $\left(\delta_{\mathrm{H}} 7.24\right)$ or the central peak of the $\mathrm{CDCl}_{3}$ triplet $\left(\delta_{\mathrm{C}} 77.00\right)$ as the internal standard. High resolution mass spectrometry data were collected on a LCT Premier time of flight mass spectrometer (Waters Corp., Milford, MA). Normal phase TLC was performed on Sorbent Technologies Silica G TLC plates $(200 \mu \mathrm{m}$, w/UV 254) using the solvent system $\mathrm{CH}_{2} \mathrm{Cl}_{2}-\mathrm{EtOAc}-\mathrm{MeOH}$ (1:8:1), and reverse phase TLC was performed on Sorbent Technologies C18 TLC plates (150 $\mu \mathrm{m}, \mathrm{w} / \mathrm{UV} 254)$ using $\mathrm{H}_{2} \mathrm{O}-\mathrm{MeOH}$ (1:1). Spots were visualized using UV light $(254 \mathrm{~nm})$ and spraying with vanillin-sulfuric acid reagent.

\subsection{Plant Material}

The plant crude extract was acquired from PhytoMyco Research Corporation, Greenville, NC in March 2009. The extract was prepared according to published procedures by sequential extraction of the dried and ground leaves of $W$. somnifera with a mixture of $\mathrm{CH}_{2} \mathrm{Cl}_{2}$ and $\mathrm{MeOH}(1: 1, \mathrm{v} / \mathrm{v})$ followed by $\mathrm{MeOH}$ and $\mathrm{H}_{2} \mathrm{O}$ to obtain three fractions (Jayaprakasam and Nair, 2003). All fractions were then combined, filtered and dried under reduced pressure. The original extract has been stored at $-20{ }^{\circ} \mathrm{C}$ in our laboratory to serve as a reference material.

\subsection{Extraction and Isolation}

The powdered, dried plant extract ( $189 \mathrm{~g}$ ) of W. somnifera was dissolved in $200 \mathrm{~mL}$ of water to form a suspension. The mixture was defatted with hexane $(2 \mathrm{~L} \times 3)$, and the aqueous phase was extracted with EtOAc $(2 \mathrm{~L} \times 6)$ and $\mathrm{BuOH}(2 \mathrm{~L} \times 3)$ to obtain $32.9 \mathrm{~g}$ of EtOAc extract and $80.0 \mathrm{~g}$ of $\mathrm{BuOH}$ extract. The EtOAc extract was then subjected to passage over a Si gel column (600 g, $32 \sim 63 \mu \mathrm{m}$, Sorbent Technologies), eluted sequentially with $\mathrm{CH}_{2} \mathrm{Cl}_{2-}$ $\mathrm{CH}_{3} \mathrm{COCH}_{3}$ solvent gradient (0-100\%) followed by $\mathrm{MeOH}$, to give eight major fractions (Fraction A-H). Fraction F was chromatographed on a Si gel $(200 \mathrm{~g}, 12 \sim 26 \mu \mathrm{m}$, Sorbent Technologies) MPLC column, eluted with $\mathrm{CH}_{2} \mathrm{Cl}_{2}-\mathrm{EtOAc}-\mathrm{MeOH}$ (40:10:1), to afford four further fractions (F1-F4). Fraction F2 was applied onto a C-18 reverse phase column (100 g, 
Sorbent Technologies), eluted with $\mathrm{MeOH}-\mathrm{H}_{2} \mathrm{O}$ (3:7) to remove the green color. The colorless fraction F2 was then separated on a Sephadex LH-20 column (200 g, GE Healthcare), eluted with $\mathrm{MeOH}$ to obtain the major components, and then purified by separation over a Si gel column (50 g, $12 \sim 26 \mu \mathrm{m}$, Sorbent Technologies), eluted with $\mathrm{CH}_{2} \mathrm{Cl}_{2}-\mathrm{MeOH}-\mathrm{EtOAc}$ (18:1:1), to yield $\mathbf{1}(5 \mathrm{mg})$. Fraction F1 was purified on a Sephadex LH-20 column (200 g, GE Healthcare), eluted with $\mathrm{MeOH}$, to afford 2,3-

didehydrosomnifericin $(21 \mathrm{mg})$. Compound withanone $(800 \mathrm{mg})$ was obtained as fine needles by recrystallization of fraction $\mathrm{D}$ from $\mathrm{CHCl}_{3}-\mathrm{CH}_{3} \mathrm{COCH}_{3}(1: 1)$. Fraction $\mathrm{E}$ was chromatographed on a Si gel column, eluted with $\mathrm{CH}_{2} \mathrm{Cl}_{2}-\mathrm{CH}_{3} \mathrm{COCH}_{3}$ (10:1), to collect twelve fractions (E1-El2), and E6 was identified as withaferin A (34 mg). The major withanolide in fraction $\mathrm{E} 7$ was obtained as a white powder yielding 3-methoxy-2,3dihydrowithaferin $\mathrm{A}(22 \mathrm{mg})$ by recystallization from $\mathrm{CHCl}_{3}-\mathrm{CH}_{3} \mathrm{COCH}_{3}(1: 1)$. E12 was separated over a C-18 reverse phase SPE column $(5 \mathrm{~g}, 20 \mathrm{~mL}$, Phenoment strata C-18), eluted with $\mathrm{MeOH}-\mathrm{H}_{2} \mathrm{O}(1: 1)$, to give a mixture of two compounds. Further purification of the mixture by HPLC using isocratic elution with $\mathrm{CH}_{3} \mathrm{CN}-\mathrm{H}_{2} \mathrm{O}$ (45:55) provided (22R)-5 formyl-6 $\beta, 27$-dihydroxy-1-oxo-4-norwith-24-en $(1.5 \mathrm{mg})$ and 2,3-dihydrowithaferin $\mathrm{A}$ (1.2 $\mathrm{mg})$. Compound $2(7.3 \mathrm{mg})$ was purified from fraction E11 by a C-18 reverse phase SPE column (5 g, $20 \mathrm{~mL}$, Phenoment strata C-18) using $\mathrm{MeOH}-\mathrm{H}_{2} \mathrm{O}(1: 1)$.

The $n-\mathrm{BuOH}$ extract was subjected to passage over a Si gel column $(2 \mathrm{~kg}, 12 \sim 26 \mu \mathrm{m}$, Sorbent Technologies), eluted sequentially with $\mathrm{MeOH}-\mathrm{CH}_{2} \mathrm{Cl}_{2}$ solvent gradient (30\%$100 \%$ ), to give 24 fractions. Fraction 4-5 was purified on a Sephadex LH-20 column ( $200 \mathrm{~g}$, GE Healthcare), eluted with $\mathrm{MeOH}-\mathrm{H}_{2} \mathrm{O}$ (8:2), to afford a withanoside-rich fraction. This faction was further purified by PTLC eluting with $\mathrm{CH}_{2} \mathrm{Cl}_{2}-\mathrm{MeOH}-\mathrm{H}_{2} \mathrm{O}$ (40:10:1) and semiprep HPLC eluting with $\mathrm{CH}_{3} \mathrm{CN}-\mathrm{H}_{2} \mathrm{O}(25: 75)$ to afford withanoside $\mathrm{IV}(5.6 \mathrm{mg})$ and withanoside $\mathrm{X}(6.3 \mathrm{mg})$.

\subsection{6a-chloro-5 $\beta, 17 \alpha$-dihydroxywithaferin A (1)}

Colorless crystal $(\mathrm{MeOH}) ; \mathrm{mp} 238-240{ }^{\circ} \mathrm{C} ;[\alpha]^{25}{ }_{546}+53.1(\mathrm{c} 0.001, \mathrm{MeOH}) ; \mathrm{UV}(\mathrm{MeOH})$ $\lambda_{\max }(\log \varepsilon) 220(3.93) \mathrm{nm}$; IR (film) $v_{\max } 3500,2980,1700,1650,1630$ and $1050 \mathrm{~cm}^{-1 ; 1} \mathrm{H}$ NMR (500 MHz, $\left.\mathrm{CDCl}_{3}\right)$ and ${ }^{13} \mathrm{C}$ NMR $\left(125 \mathrm{MHz}, \mathrm{CDCl}_{3}\right)$ see Table 1; ESIMS m/z 523 $[\mathrm{M}+\mathrm{H}]^{+}$; HRESIMS $m / z$ 523.2440 (calc. for $\mathrm{C}_{28} \mathrm{H}_{40} \mathrm{ClO}_{7}, 523.2463$ ).

\section{Supplementary Material}

Refer to Web version on PubMed Central for supplementary material.

\section{Acknowledgments}

The authors acknowledge financial assistance from the Center for Cancer Experimental Therapeutics NIH Grant 5P20 RR015563-10 (to B.N.T.) and the University of Kansas fund KU 2506014-910/099 (to B.N.T.). The authors thank Dr. Victor Day, Director of the Molecular Structures Group, University of Kansas, for the X-ray analysis.

\section{References}

Al-Hindawi MK, Al-Deen IH, Nabi MH, Ismail MA. Anti-inflammatory activity of some Iraqi plants using intact rats. J Ethnopharmacol. 1989; 26:163-168. [PubMed: 2601356]

Arora S, Dhillon S, Rani G, Nagpal A. The in vitro antibacterial/synergistic activities of Withania somnifera extracts. Fitoterapia. 2004; 75:385-388. [PubMed: 15159002]

Bessalle R, Lavie D. Withanolide C, a chlorinated withanolide from Withania somnifera. Phytochemistry. 1992; 31:3648-3651.

Bhattacharya SK, Bhattacharya A, Sairam K, Ghosal S. Anxiolytic-antidepressant activity of Withania somnifera glycowithanolides: an experimental study. Phytomedicine. 2000; 7:463-469. [PubMed: 11194174] 
Bhattacharya SK, Satyan KS, Ghosal S. Antioxidant activity of glycowithanolides from Withania somnifera. Indian J Exp Biol. 1997; 35:236-239. [PubMed: 9332168]

Choudhary MI, Abbas S, Jamal SA, Atta ur R. Withania somnifera - a source of exotic withanolides. Heterocycles. 1996; 42:555-563.

Choudhary MI, Hussain S, Yousuf S, Dar A, Mudassar, Atta ur R. Chlorinated and diepoxy withanolides from Withania somnifera and their cytotoxic effects against human lung cancer cell line. Phytochemistry. 2010; 71:2205-2209. [PubMed: 21044792]

Christina AJM, Joseph DG, Packialakshmi M, Kothai R, Robert SJH, Chidambaranathan N, Ramasamy M. Anticarcinogenic activity of Withania somnifera Dunal against Dalton's ascitic lymphoma. J Ethnopharmacol. 2004; 93:359-361. [PubMed: 15234777]

Davis L, Kuttan G. Immunomodulatory activity of Withania somnifera. J Ethnopharmacol. 2000; 71:193-200. [PubMed: 10904163]

Dhuley JN. Adaptogenic and cardioprotective action of ashwagandha in rats and frogs. J Ethnopharmacol. 2000; 70:57-63. [PubMed: 10720789]

Geetha KM, Harish MS. Antistress activity of ethanolic extract of Withania somnifera and Ocimum sanctum. Oriental J Chem. 2006; 22:719-721.

Gottlieb HE, Kirson I. Carbon-13 NMR spectroscopy of the withanolides and other highly oxygenated $\mathrm{C}_{28}$ steroids. Org Magn Res. 1981; 16:20-25.

Jayaprakasam B, Nair MG. Cyclooxygenase-2 enzyme inhibitory withanolides from Withania somnifera leaves. Tetrahedron. 2003; 59:841-849.

Matsuda H, Murakami T, Kishi A, Yoshikawa M. Structures of withanosides I, II, III, IV, V, VI, and VII, new withanolide glycosides, from the roots of Indian Withania somnifera Dunal and inhibitory activity for tachyphylaxis to clonidine in isolated guinea-pig ileum. Bioorg Med Chem. 2001; 9:1499-1507. [PubMed: 11408168]

Mirjalili MH, Moyano E, Bonfill M, Cusido RM, Palazon J. Steroidal lactones from Withania somnifera, an ancient plant for novel medicine. Molecules. 2009; 14:2373-2393. [PubMed: 19633611]

Nagashayana N, Sankarankutty P, Nampoothiri MRV, Mohan PK, Mohanakumar KP. Association of L-DOPA with recovery following Ayurveda medication in Parkinson's disease. J Neurol Sci. 2000; 176:124-127. [PubMed: 10930594]

Nittala SS, Lavie D. Studies on the $5 \beta, 6 \beta$-epoxide opening in withanolides. J Chem Soc Perkin Trans. 1982; 1:2835-2839.

Nittala SS, Vande Velde V, Frolow F, Lavie D. Chlorinated withanolides from Withania somnifera and Acnistus breviflorus. Phytochemistry. 1981; 20:2547-2552.

Owais M, Sharad KS, Shehbaz A, Saleemuddin M. Antibacterial efficacy of Withania somnifera (ashwagandha) an indigenous medicinal plant against experimental murine salmonellosis. Phytomedicine. 2005; 12:229-235. [PubMed: 15830846]

Pelletier SW, Mody NV, Nowacki J, Bhattacharyya J. Carbon-13 nuclear magnetic resonance spectral analysis of naturally occurring withanolides and their derivatives. J Nat Prod. 1979; 42:512-521.

Pramanick S, Roy A, Ghosh S, Majumder HK, Mukhopadhyay S. Withanolide Z, a new chlorinated withanolide from Withania somnifera. Planta Med. 2008; 74:1745-1748. [PubMed: 18988152]

Samadi AK, Tong X, Mukerji R, Zhang H, Timmermann BN, Cohen MS. Withaferin A, a cytotoxic steroid from Vassobia breviflora, induces apoptosis in human head and neck squamous cell carcinoma. J Nat Prod. 2010; 73:1476-1481. [PubMed: 20726569]

Sankar SR, Manivasagam T, Singh VA, Krishnamurti A, Ramanathan M. Prophylactic efficacy of Withania somnifera against MPTP induced Parkinson's disease in mice. J Cell Tissue Res. 2007; 7:975-979.

Sumantran VN, Chandwaskar R, Joshi AK, Boddul S, Patwardhan B, Chopra A, Wagh UV. The relationship between chondroprotective and antiinflammatory effects of Withania somnifera root and glucosamine sulphate on human osteoarthritic cartilage in vitro. Phytother Res. 2008; 22:1342-1348. [PubMed: 18697233]

Zhao J, Nakamura N, Hattori M, Kuboyama T, Tohda C, Komatsu K. Withanolide derivatives from the roots of Withania somnifera and their neurite outgrowth activities. Chem Pharm Bull. 2002; 50:760-765. [PubMed: 12045329] 


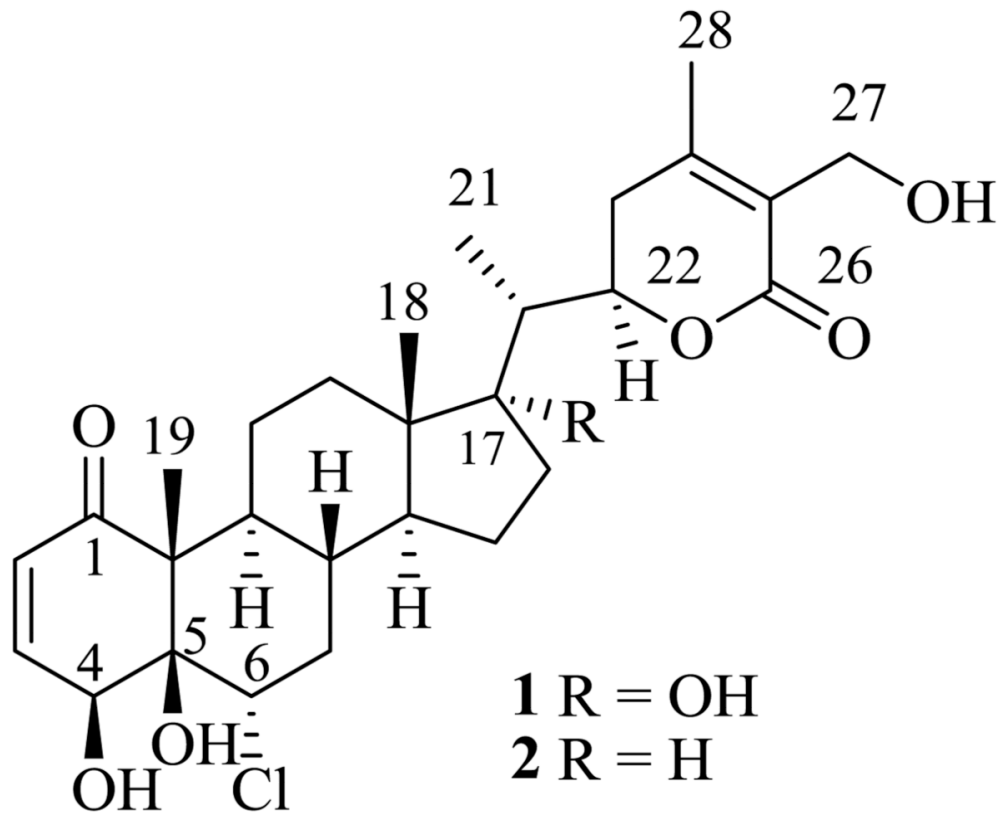

Fig. 1.

Chlorinated withanolides from Withania somnifera. 


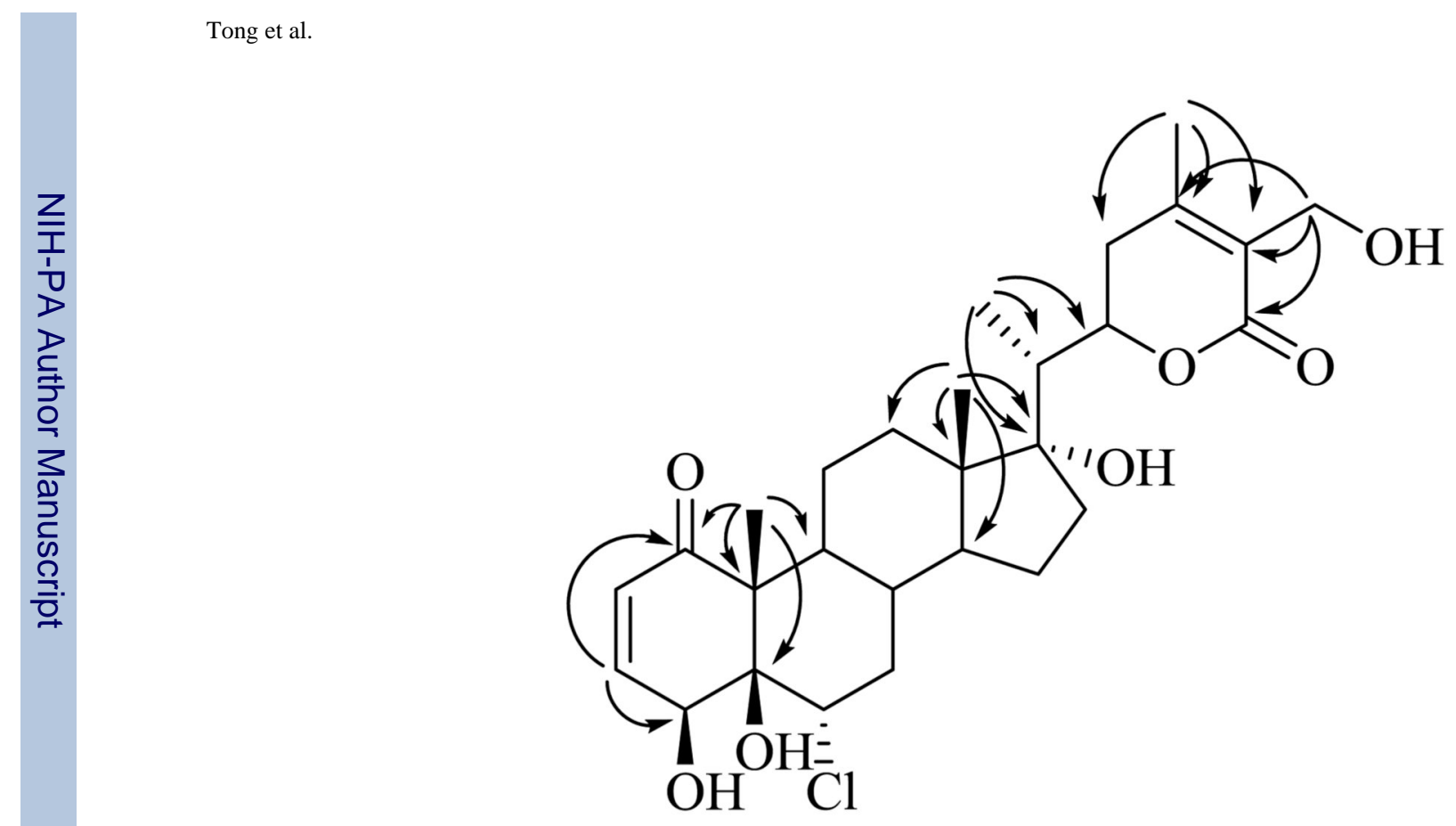

Fig. 2.

Key HMBC correlations of compound $\mathbf{1}$. 


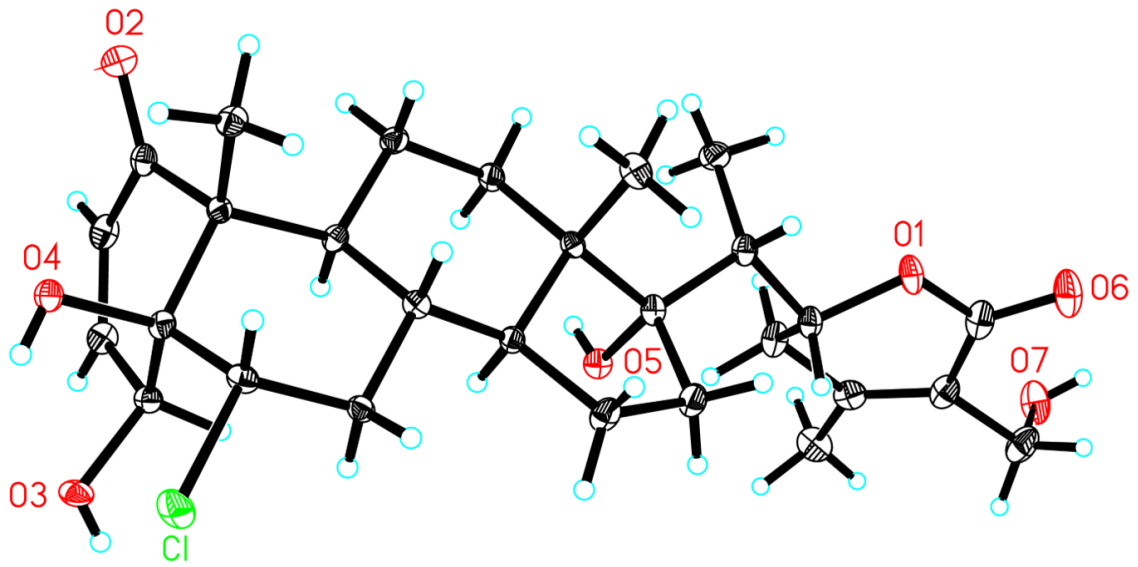

Fig. 3.

ORTEP view of chlorinated withanolide $\mathbf{1 .}$ 
Table 1

${ }^{1} \mathrm{H}$ and ${ }^{13} \mathrm{C}$ NMR data of chlorinated withanolides $\mathbf{1}$ and $\mathbf{2}$ in $\mathrm{CDCl}_{3}$.

\begin{tabular}{|c|c|c|c|c|}
\hline \multirow[t]{2}{*}{ No. } & \multicolumn{2}{|l|}{1} & \multicolumn{2}{|l|}{2} \\
\hline & ${ }^{1} \mathbf{H}^{a}$ & ${ }^{13} C^{b}$ & ${ }^{1} \mathbf{H}^{a}$ & ${ }^{13} C^{b}$ \\
\hline 1 & & 200.2 & & 200.1 \\
\hline 2 & $6.02 \mathrm{dd}(10.4,2.2)$ & 127.8 & $6.00 \mathrm{dd}(10.4,2.2)$ & 127.8 \\
\hline 3 & $6.50 \mathrm{dd}(10.4,2.5)$ & 142.8 & $6.47 \mathrm{dd}(10.4,2.5)$ & 142.8 \\
\hline 4 & $5.06 \mathrm{br} \mathrm{s}$ & 66.1 & $5.01 \mathrm{br} \mathrm{s}$ & 66.2 \\
\hline 5 & & 78.1 & & 78.1 \\
\hline 6 & $4.45 \mathrm{dd}(12.7,4.6)$ & 66.5 & $4.42 \mathrm{dd}(12.5,4.9)$ & 66.7 \\
\hline 7 & $2.30 ; 1.71$ & 39.3 & $2.30 ; 1.63$ & 39.4 \\
\hline 8 & 1.63 & 35.2 & 1.62 & 35.1 \\
\hline 9 & 1.27 & 45.3 & 1.27 & 45.8 \\
\hline 10 & & 57.1 & & 57.2 \\
\hline 11 & $1.33 ; 0.97$ & 22.4 & $1.33 ; 0.90$ & 22.7 \\
\hline 12 & $1.58 ; 1.31$ & 31.6 & $1.89 ; 1.04$ & 39.0 \\
\hline 13 & & 48.3 & & 43.2 \\
\hline 14 & 1.64 & 49.6 & 1.05 & 55.3 \\
\hline 15 & $1.71 ; 1.21$ & 23.3 & $1.63 ; 1.18$ & 24.0 \\
\hline 16 & $1.97 ; 1.68$ & 36.5 & $1.67 ; 1.37$ & 27.2 \\
\hline 17 & & 84.8 & 1.07 & 51.8 \\
\hline 18 & $0.78 \mathrm{~s}$ & 14.8 & $0.65 \mathrm{~s}$ & 11.8 \\
\hline 19 & $1.27 \mathrm{~s}$ & 9.9 & $1.24 \mathrm{~s}$ & 9.9 \\
\hline 20 & 2.26 & 42.6 & 1.87 & 38.7 \\
\hline 21 & $0.99 \mathrm{~d}(7.0)$ & 9.4 & $0.95 \mathrm{~d}(7.0)$ & 13.3 \\
\hline 22 & $4.65 \mathrm{~m}$ & 78.9 & $4.38 \mathrm{~m}$ & 78.6 \\
\hline 23 & $2.47,1.91$ & 32.9 & $2.45,1.93$ & 29.8 \\
\hline 24 & & 154.2 & & 152.7 \\
\hline 25 & & 125.2 & & 125.7 \\
\hline 26 & & 167.0 & & 166.9 \\
\hline 27 & $4.39 \mathrm{~d}(12.6) ; 4.35 \mathrm{~d}(12.6)$ & 57.3 & $4.37 \mathrm{~d}(12.6) ; 4.33 \mathrm{~d}(12.6)$ & 57.4 \\
\hline 28 & $2.03 \mathrm{~s}$ & 20.0 & $2.00 \mathrm{~s}$ & 20.0 \\
\hline
\end{tabular}

${ }^{a} \delta(\mathrm{ppm}) 500 \mathrm{MHz}$; multiplicities; $J$ values $(\mathrm{Hz})$ in parentheses.

$b_{\delta(\mathrm{ppm})} 125 \mathrm{MHz}$. 